cimen of the basking shark had been captured entangled in some salmon nets off the south shore of Conception Bay in August, 1876 . Mr. Harvey thinks that the shark was probably feeding on caplin, as the Bay was full of shoals of this little fish. The on captin, as dried specimen were about a quarter of an inch in length, though probably in the fresh state they hardly projected beyond the gums. For other details we would refer Mr. Harvey to Prof. Pavesi's memoir quoted above, with the hope that he may still further continue his interesting investigation of the fauna of Newfoundland.-ED.]

\section{The "Challenger" Collections}

$I_{T}$ is a rather remarkable proof of the increased interest taken in natural science, that no one worth listening to has ventured to make a remark in disparagement of the Challenger expedition, or to utter a growl at the liberal support accorded to it from the national fund. This goes far to show that extensive classes of the community are able in various degrees to appreciate the objects and results of the expedition. One of these results is the collection of specimens in natural history. It is on the final destination of this collection that I wish to offer a suggestion. Within my own recollection it would have been difficult to name half.a-dozen public museums in Great Britain and Ireland where a series of objects, such as could be formed out of the duplicates in the Challenger collection, would be sure of meeting with a suitable reception. The number now would probably exceed a score, exclusive of museums in public colleges and schools; at a rough estimate the total number may be put down as at least forty. The supporters of these museums, as public tax-payers, have willingly contributed towards the expenses of the late noble and successful expedition; but it is not alone on this ground that I would respectfully urge a recognition of their claim to share in the treasure trove, but rather on the ground of the impulse that might be given to the study of natural science, and to the cordial support of plans for further expeditions of a like character.

For reasons which will be obvious on reflection, it would be a great saving of time and trouble to those engaged in the arrangement of the specimens if public museums were invited to send in, on or before a certain fixed day, to some central board, an expression of their desire to participate in the benefit of the Challenoer collections, at the same time stating the grounds of their clairi, and the department in natural science in which they would prefer to receive contributions. The examination and determination of these applications must be a work of time, therefore the sooner the plan is set on foot the better. Monographs will probably be published, and museums will purchase them; but they cannot buy the specimens, and the value of the monographs to any institution will be increased tenfold by the possession of authenticated specimens of some of the species described. Of course there are universities and other centres of scientific teaching which must come first; but I respectfully and earnestly protest against drawing the line of exclusion too strin. gently. There is now a -great national opportunity for encouraging in a substantial way the instruction, given in lectures and science classes, which often languishes for want of illustrations. I know of stores of natural history treasures. If only they had been dispensed in wisely apportioned nuclei, how valuable, by this time, might have been the collections accumulated round them. If selection amongst the claimants be impossible, might not series be made up for loan or sale? It will be unworthy of the way in which the Challenzer work has been done, if even a single Rhizopod shall find its resting-place in a dust-hole.

HENRY H. HiGGINS

\section{Traces of Pre-Glacial Man in America}

IN NATURE, vol. xv. p. 87, you bave given an outline of a paper by Prof. Hughes, read before the Cambridge Philosophical Society, "in which he criticised the evidence offered to support the view that man existed on the earth during or before the glacial period." As concerning the question of the antiquity of man in North America, I would first call attention to the remarks on this subject by the late Prof. Jeffries Wyman, the most cautious and careful of archrologists, who writes:" "The ancient remains found in California, brought to the notice of the scientific world by Prof. J. D. Whitney, and referred by him to

2 "Fresh Water Shell-mounds of Florida." Fourth Memoir of Peabody Academy, Salem, Mass., U.S.A., December 2874 , p. 45. the Tertiary period, \&c," to which is added a footnote, that "the ample evidence collected by Prof. Whitney, but not yet published, substantiates the opinion given above weith regard to a are. The omission of the Calaveras sketll would not weaken the evidence as to the existence of man in the Tertiary' period in California." Inasmuch as the Glacial period occurred at the close of the Tertiary period, if Prof. Whitney's discoveries are conclusive, as to this side of the Atlantic, does it not follow that man must have existed, certainly in Asia, prior to the glacial epoch? We are assured by all ethnologists, that man migrated from Asia to America, and now we are offered proofs of his American sojourn, of a date preceding the occurrence of glacial conditions. Speaking of the Eskimo, Dr. Peschel remarks" : "The identity of their language with that of the Namollo, their skill on the sea, their domestication of the dog, their use of the sledge, the Mongolian type of their faces, their capability for higher civilisation, are sufficient reasons for answering the question, whether a migration took place from Asia to America, or conversely from America to Asia, in favour of the former alternative; yet such a migration from Asia, by way of Behring's Straits, must have occurred at a much later period than the first colonisation of the Nezt World from the Old one." Again, in speaking of the Red Indians, he remarks": "It is not impossible that the first migrations took place at a time when what is now the channel of Behring's Straits was occupied by an istbmus. The climate of those northern shores must then have been much milder than at the present day, for no currents from the Frozen Ocean could have penetrate into the Pacific." This reference to a milder climate must necessarily refer to the genial warmth of Pliocene times; for scarcely under other circumstances can we find time enough to explain the various phases of lost civilisations, especially in South America. Whether or not the supposed traces of glacial and pre-glacial man in Europe be really such-if the archeology of North America has, so far, been correctly interpreted-then, unless they have been totally deatroyed, unquestionable traces of such early main will be ultimately discovered; but if such "finds" should never gladden Eaglish archrologists, the earnest workers in America have rendered it certainly true that in Asia, and doubtless in Europe, man did exist during the closing epoch of the Tertiary period, if there is, indeed, no error in the supposition that our American aborigines migrated from the Old World.

Trenton, N.J., U.S.A., December 16,1876 CHAS. C. ABвOTT

\section{Glacial Drift in Califortia}

IN a recent letter from my brother residing in California, he describes a curious moraine or drift formation, which may, perhaps, be as new to some of your readers as it was to myself. $\mathrm{H}$ - is description, with a few verbal alterations, is as follows :-

"The plains for a distance of from five to twenty miles from the foot of the Sierra Nevada are covered with what are locally termed 'hog-wallows.' The surface thus designated may" be represented on a small scale by covering the bottom of a large flat dish with eggs distributed so that their longer axes shall lie at various angles with one another, and then filling the dish with fine sand to a little more than balf the height of the eggs. The surface of the sand and of those parts of the eggs which rise above it, gives a fair representation of the 'hog-wallow' land. The mounds, which are represented by the eggs, vary from two to five feet in height, and from ten to thirty feet in diameter, some being nearly circular, some oval, while others are more irregular in shape. Those nearest the foot-bills are the largest, and they gradually diminish in size as they extend out into the plain. They are composed of gravel and boulders of irregular sizes, generally covered with a surface-soil, but sometimes bare. These tracts, which are very extensive in some parts of the State, have been till lately unexplained; but it is now generally admitted that they are due to the retreat of the broad foot of the glacier, leaving behind it a layer of detrtis or moraine-matter, which has become arranged in its present form by the innumerable rills that issued from the retiring sheet of ice. A living glacier has lately been discovered far up in the Sierra Nevada, near the head waters of the San Joaquim River."

Perhaps some of your geological readers may know it any similar formations occur elsewhere; and may favour us with their views as to whether scextensive and uniform a deposit could be due to a retreating glacier alone, or would not rather require the agency

I "Races of Man," by Dr. Oscar Peschel. Neww York, 1876 , p. 396 . Ibid, p. 400 
of a temporary submergence to spread out the détris with such uniformity. During the retreat of the waters, pluvial action might perluaps wash away the softened soil in the regular manner deccribed. Alfred R. Wallace

The Number of Species of Insects

PROF.HUXLEX is very much within the mark when he estimates the species of insects at "about 100,000, if not more." Were I to estimate the number of described species at 200,000 , I believe the figures would also fall short of the truth, even allowing a liberal margin for synonyms. In one order alone (Coleoptera) it is tstimated that 80,000 species have been described.

$\tau$ could enlarge upon the bearing these figures have upon theories on the geograpinical distribution of animals, but content mysclf with the remark that the groups of insects selected by writers on the subject are those in which colour is most prominent and structure least differentiated.

Lewisham, January 12

R. MCLACHLAN

[WE sent the above to Prof. Huxley, who has appended the following note.-" It was not my object to give an accurate estimate of the total number of species of insects. Gerstaecker, in the new edition of Broun's 'Thier-reich,' gives 200,000 as the total number of species of Arthropola; ; but I dare say that Mr. McLachlan has good grounds for the claim he puts in for insects alone.

$$
\text { "T. H. HUXLEY"-ED.] }
$$

\section{Meteor}

Pirecisely at 6 P.M., on the Igth inst., I saw a splendid moteor traverse the sky from a point about midway between Orion's belt and the Pleiades to a point directly under the moon, and about $10^{\circ}$ above the horizon. It was pure white and dazzling, lasted about five seconds, emitted no sparks, except at the moment of disappearance, and was about half the size of the moon at the time.

Bray, Co. Wicklow, January $2 \mathrm{I}$

Diurnal Barometric Range at Low and Figh Levels

You notice under this head (voi. xv. p. 887 ) of my paper on the daily inequalities of the barometer at Mount Washington and Portland, Maine, has hit a blot of which I was unconscions until now. Had I been more than a student writing one of his first essays in meteorology, I should probably, like yourself, have suspected something wrong in the Portland curve. The morning maximum and the afternoon minimum, as you point vut, occur very much earlier than is usual.

Differences varying from $+0^{\circ} 027$ inch to $-0^{\circ} 004$ inch between your averages of General Myer's figures and those griven in my paper did not surprise me, as mine were intended to represent the temperature of $60^{\circ} \mathrm{F}$., while you have probably talien the observations ejther as already reduced to $32^{\circ}$, or have yourself reduced then to this temperature. My own impression is and was that the printed observations are not corrected for temperature, and in order to make the comparison with as little chance as possible in the original figures for the three stations I brought each to something near a mean temperature for the three attachicd thermometers. Unfortunately, and here cones the blot, I now find that, by some mischance, in taking out the differences for Portland the external temperatures were taken instead of those by the attached thermometer. I exceedingly regret this, and shall as early as practicable make the required correction.

Fortunately this error does not affect the purport of my paper or the suggestions which I offer in it towards the explanation of the long-vexed question of the cause or causes of the daily inequality of the barometer.

An acquaintance with the variations of the daily barometric curves, which depend on change of season and difference of locality, would undoubtedly be of assistance in drawing these curves when the observations for only a few hours are given, but the six hours for which the Portland figures are given are so well distributed as to leave little uncertainty as to the general form of the curve in this case. I should not, howrever, be satisfied with any curve for the Purtland observations which, when anaiysed by the usual formula and reconstructed from the co-efficients thus obtained, did not reproduce the original observations, and also the interpolated values for the other hours, within a limit of error of 0.001 inch. Unless your curve can stand this test I shall not be satisfied with your deductions as to the epochs of maximum and minimum values, Haying had much experience in drawing such curves, I venture to assert that the Portland observations, whether taken as they are printed or after a correction for tem perature, will still give the morning maximum and afternoon minimum of the barometer much earlier than is usually the case in this country. If my paper draws attention to any singularity of this kind it will mitigate the disappointment caused by the mistake in the temperature correction.

I append the times of maxima and minima for Portland, May, I 872 , as corrected ; also similar data for five years at the Naval Observatory, Washington, U.S., and for Oxford, England.

Times of Daily Maxima and Minima of the Barometer for the Month of May.

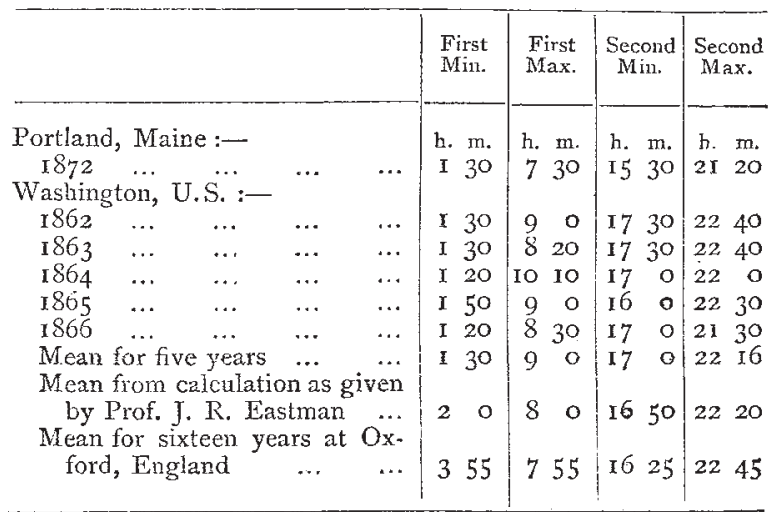

Liverpool, January 5

W. W. RUNDELL

\section{Former Climates}

IT appears to be established that a climate favourable to the growth of coal plants and coral builders has prevailed in latitudes where the sun now sinines for about seven months out of twelve.

Without inquiring how it came about that a warm sea once washed polar coasts, it would be interesting to learn whether the plants and animals concerned in the production of coal forests and coral reefs can flourish under these conditions of light supply.

Holmwood, Putney Hill D. PIDGEON

\section{Tape-worms of Rabbits}

HAVING had occasion to dissect a number of wild rabbits, $I$ have been surprised to find that the majority of them are infested with a large species of tape-worm. Can any of your readers inform me whether the life-history of this parasite has ever been made out? The case appears to be a remarkable one, because the host cannot here be suspected of ever taking animal food. Unless, therefore, we suppose that the tape-worm of a rabbit differs from other tape-worms in not passing through a hydatid stage, it becomes difficult to explain the very general occurrence of this species. George J. Romanes

\section{POLARISCOPE OBYECTS}

THE following is an interesting combination :-When the polariser and analyser are crossed, insert a concave plate of quartz cut parallel to the axis, with its axis inclined at $45^{\circ}$ to that of the polariser, add to this a quartz wedge cut also parallel to the axis, having its axis placed perpendicular to that of the concave plate. The coloured circles, shown by the concave plate alone, will be seen to be displaced in the direction of the thicker edge, to a distance dependent upon the angle of the wedge. Also, as the wedge is made to slide in or out, the circles will be seen to expand or contract, according as the thicker or thinner part of it is presented to the field of view.

The explanation of this is to be found in the fact that a combination of two crystalline plates is optically equivalent to a single plate, whenever the axes of the plates are either parallel or perpendicular to one another. This follows immediately from a comparison of the mathematical expressions for the intensity of the light at any 